\title{
Anogenital Distance Increased
}

National Cancer Institute

\section{Source}

National Cancer Institute. Anogenital Distance Increased. NCI Thesaurus. Code C124548.

An indication that the anogenital distance is greater than the norm. 